\title{
How do things look to the color-blind?*
}

\author{
Alex Byrne and David R. Hilbert \\ GENTLEMEN,-Colour-blindness is not a good name for the condition to which it \\ is applied...
}

(Edridge-Green 1911: 9)

\section{Introduction}

Our question is: how do things look to the color-blind? But what does that mean?

Who are the "color-blind"? Approximately $7 \%$ of males and fewer than $1 \%$ of

females (of European descent ${ }^{1}$ ) have some form of inherited defect of color vision, and as a result are unable to discriminate some colored stimuli that most of us can tell apart.

('Color defective' is an alternative term that is often used; we will continue to speak with the vulgar.) Color vision defects constitute a spectrum of disorders with varying degrees and types of departure from normal human color vision. One form of color vision defect is dichromacy: by mixing together only two lights, the dichromat can match any light, unlike normal trichromatic humans who need to mix three. The most common form of dichromacy (afflicting about $2 \%$ of males) is red-green color blindness, or red-green dichromacy, which itself comes in two varieties. A red-green dichromat will not be able to distinguish some pairs of stimuli that respectively appear red and green to those with normal color vision. For simplicity we will concentrate almost exclusively on red-green color blindness. ${ }^{2}$

In a philosophical context our question is liable to be taken two ways. First, it can be straightforwardly taken as a question about visible properties of external objects like

\footnotetext{
* Thanks to an audience at Florida State University, and to Justin Broackes, Jonathan Cohen, and Mohan Matthen for helpful comments. We dedicate this paper to Larry Hardin for all he's done to promote empirically informed discussions of color by philosophers.

${ }^{1}$ See Sharpe et al. 1999: table 1.5 (this gives figures only for red-green deficiencies; as Sharpe et al. discuss, other kinds of deficiency are exceptionally rare).

${ }^{2}$ Anomalous trichromacy is a less severe defect which comes in two varieties, corresponding to each of the two varieties of red-green dichromacy. Although we are focusing on red-green dichromacy some of the data we report also covers anomalous trichromats.
} 
tomatoes. Do tomatoes look colored to dichromats? If so, what color? Second, it may be interpreted as the more elusive - although closely related — question of "what it's like" to be color-blind. Forget about tomatoes-what is a dichromat's experience like? ${ }^{3}$ This paper addresses the first question and, for reasons of space, does not explicitly address the second. Put another (arguably equivalent) way, we are asking what colors are represented by a dichromat's experience.

Having now identified the "color-blind", and the straightforward way in which our question should be taken, a further point of clarification might be helpful. Imagine a bright blue car parked in an underground garage illuminated by orange lighting. Bright blue objects under this lighting look quite distinctive. Those accustomed to the garage can tell by looking whether something is bright blue. They may even say, pointing to the car, "That looks bright blue". Those with more linguistic scruples will perhaps prefer instead to say "That looks to be bright blue", or "That looks as if it is bright blue". This distinction, of course, is sometimes explained in terms of various "senses" of 'looks'. In the alleged phenomenal sense of 'looks', the car looks bright blue in sunlight, but bluishblack in the garage. ${ }^{4}$ Whether or not 'looks' in fact has a special phenomenal sense, there is clearly an important difference between viewing the car in sunlight, and viewing it in the garage, even if one is inclined to say that it looks bright blue both times. 'Looks' in our question is to be stipulatively interpreted so that the following is true: in the garage, the car looks bluish-black and does not look bright blue.

With our question clarified, we can now briefly outline the two main candidate answers. On what we will call the Reduction View, a red-green dichromat enjoys a reduced range of normal color appearances. On the Standard version of the Reduction

\footnotetext{
${ }^{3}$ If a dichromat's color experiences are a subclass of the normal kind, then there is no obvious "in principle" barrier to knowing what dichromatic experience is like. But if a dichromat's color experiences quite different from the normal kind, then (according to many philosophers), we can never know what they are like. Relatedly, a dichromat can never know what the full range of normal color experiences are like. Recall Fred, the forgotten hero of "Epiphenomenal Qualia"-subsequently eclipsed by his co-star Mary. "Fred's optical system is able to separate out two groups of wavelengths in the red spectrum as sharply as we are able to sort out yellow from blue...We are to Fred as a totally red-green colour-blind person is to us" (Jackson 1982: 274).

${ }^{4}$ See Chisholm 1957: ch. 4, Jackson 1977: ch. 2, Thau 2002: 226-31.
} 
View (which is orthodoxy, if anything is) things look yellow and blue to dichromats, but not red or green. On the alternative Alien View a red-green dichromat does not see yellow or blue (or, for that matter, red or green), but some other colors entirely; as Hardin puts it, "what he sees is incommensurable with what we see" (1993: 146). Deciding between these views turns out to be no simple matter.

The dispute between the Reduction and Alien views, we should emphasize, turns on hue, not saturation or lightness. There is no reason for taking dichromats to be blind to saturation or lightness; in particular, we will assume throughout that dichromats see completely desaturated colors - white, black, and grey. ${ }^{5}$ (Following common practice we will sometimes use 'color' to mean hue: the context should make this clear.)

Not surprisingly, color scientists have addressed the question of this paper, and at least some are skeptical about the prospects of answering it. A (slightly dated) example is provided by Boynton's excellent 1979 text, Human Color Vision, which includes a section titled, "What do Red-Green Defective Observers Really See?" After a couple of pages of discussion Boynton ends by saying that "the issue of what dichromats 'really' see probably can never be fully resolved" (1979: 382; see also Kaiser and Boynton 1996: 456). ${ }^{6}$ In the optimistic camp, a more recent paper in Nature, "What do colour blind people see?" (Viénot et al. 1995; see also Brettel et al. 1997), contains color illustrations purporting to show to normal subjects what a picture of flowers would look like to dichromats. Similar illustrations can be found on many websites. ${ }^{7}$

The Reduction and Alien Views lend support to different answers to the question of veridicality: do red-green dichromats see the true colors of things, or do they suffer from many color illusions? John Dalton, the great British chemist, produced the first

\footnotetext{
${ }^{55}$ One reason is given by Hurvich: dichromats report seeing colors "of the same general nature as the grayness of 'night vision"' (1981: 244). 'Same general nature as' should be construed as 'similar to', not as 'identical with': the greyness of 'night vision' is not the same as the greyness of 'day vision' (see note 25 below).

${ }^{6}$ Hardin reads Boynton very differently from us, citing the section referred to in support of the Standard Reduction View (1993: 146).

${ }^{7}$ See, in particular, http://www.vischeck.com/, which uses the algorithm of Brettel et al. 1997. See also Brettel's page http://www.tsi.enst.fr/ brettel/colourblindness.html.
} 
systematic investigation of color blindness and was red-green color-blind himself (hence 'Daltonism'). In the first published account of red-green dichromacy, Dalton reported that the pink flower of Geranium zonale "appeared to me almost an exact sky-blue by day" (1977: 520). ${ }^{8}$ On the face of it, the flower is simply pink, and not also sky-blue. So, if we take his words at face-value, Dalton was suffering from a color illusion. Alternatively, perhaps the flower appeared to be some other ("alien") color to Dalton, and moreover one that is not a contrary of pink. On this view, there need be no illusion, although Dalton did make a (perhaps understandable) error in using an ordinary color word to describe the flower's appearance. (We will return to Dalton later, in §2.3.)

The next section supplies some background on color vision and color blindness, and examines four pieces of evidence bearing on our question: similarity judgments, the use of color language, the opponent-process theory of color vision, and (rare cases of) unilateral and acquired dichromacy. Similarity judgments and color language are of little help; the opponent-process theory and the two unusual forms of dichromacy apparently support the Standard Reduction View. $§ 3$ examines the Reduction View in more detail, including the issue of veridicality just mentioned. $§ 4$ turns to the Alien View and evaluates two arguments for it. $\S 5$ returns to the Reduction View and argues that it needs revision. Rather surprisingly, when the Reduction View is appropriately amended, it turns out to be a version of the Alien View! §6 sums up.

\section{Background: color vision and color blindness}

\subsection{Trichromacy and the CIE chromaticity diagram}

The normal human eye contains three kinds of cones, photoreceptors used for color vision. (The rods, photoreceptors used for vision in dim light, play no significant role. ${ }^{9}$ ) Cones contain photopigments that enable the cone to respond to light. The three cone types are distinguished by their respective photopigments, which are sensitive to different

\footnotetext{
${ }^{8}$ Geranium zonale, as Dalton calls it, is the "horsehoe cranesbill”, now named 'Pelargonium zonale' (Hunt et al. 1995: 987, n.4).

${ }^{9}$ However, rods and cones do interact (Stabell and Stabell 1998, Buck et al. 2006, Thomas and Buck 2006); what's more, a recent study reports "distinct color appearances mediated exclusively by rods" (Pokorny et al. 2006) (see also note 21).
} 
parts of the spectrum. The L-cones are maximally sensitive to long wavelength (yellowish-green) light, the M-cones to middle wavelength (green) light, and the S-cones to short wavelength (bluish-violet) light. Although cones are more likely to respond to light of certain wavelengths than others, this difference can be compensated by a difference in intensity. For example, if one M-cone is stimulated by low intensity light of wavelength $530 \mathrm{~nm}$ (close to its peak sensitivity), and another M-cone is stimulated by an appropriately selected high intensity light of wavelength $450 \mathrm{~nm}$, the two cones will respond identically. The individual cone responses, then, do not contain any information about wavelengths (other than information about very broad bands). Wavelength information, and so information about the colors of things, is obtained by comparing the outputs of the different cones.

Consider a color matching experiment: the observer views an illuminated disc divided in two horizontally. The test light appears in the upper semicircle; the appearance of the lower semicircle is the product of three primary lights. The observer's task is to adjust the individual intensities of the three primary lights so that the two semicircles match. (The three primaries have been chosen so that no two can match the third.) Then the observer will always be able to match the test light. Put more precisely: sometimes a match will not be achieved simply by adjusting the three primaries, but will require transferring one primary so that it mixes with the test light, not with the other two primary lights. Since two primary lights will not suffice for a match, normal human color vision is trichromatic.

This empirical result about matching is a consequence of the fact that there are three cone types ("retinal" trichromacy, as opposed to the just-mentioned "functional" trichromacy), together with some other simple assumptions. ${ }^{10}$ It allows us to represent any test light using three coordinates, specifying the intensity of the primaries required to match the test light. A test light might be represented by $(-2,1,3)-1$ unit of the second primary, 3 of the third, and -2 of the first (that is, 2 units of the first primary added to the test light). It is convenient — or was in 1928 when the matching data were first obtained-

\footnotetext{
${ }^{10}$ For instance, that cones of the same type have exactly the same spectral sensitivity. This simple assumption is actually too simple: for this and other complications, see MacLeod 1985.
} 
to get rid of the negative numbers by a linear transformation. Any test light is then represented by three positive coordinates, which we can think of as specifying the intensities of three "imaginary" primaries required for a match.

Since every test light can be assigned three coordinates, it has a location in a three dimensional space, with the axes representing the intensity of the corresponding primary. If the (imaginary) primaries are those chosen by the Commission Internationale de l'Eclairage (CIE), and if the matching data is taken from a certain small group of Englishmen, viewing a stimulus of two degrees (about the size of a quarter at arm's length) against a dark neutral background, then the resulting space is the $1931 \mathrm{CIE}$ tristimulus space, with every test light assigned three tristimulus coordinates. Because wavelength information is lost at the retina, due to the broad-band response of the cones, numerous physically different lights will have the same tristimulus values - the phenomenon of metamerism.

The tristimulus space is sometimes called a color space, which can be misleading. It is a space of lights (or stimuli more generally ${ }^{11}$ ), not colors. (The Natural Color System space is an example of true color space. ${ }^{12}$ ) Further, there isn't a natural way of transforming the tristimulus space into a color space. With the assumption that every light with the same tristimulus values has the same color, the tristimulus space could be converted into a literal color space by taking the items in the space to be the colors of the lights, whatever they are. But this assumption is not at all plausible. More importantly, the tristimulus space is not any kind of color appearance space - the space does not

\footnotetext{
${ }^{11}$ Stimuli like colored papers can be assigned tristimulus values provided the illumination and viewing conditions are specified.

${ }^{12}$ See, e.g., Hardin 1993: 116-9. A color space is a comprehensive representation of the relations of similarity among colors. The representation is spatial in the sense that degrees of similarity are represented by distances in the space. Actual color spaces constructed by color scientists are motivated by concerns that often lead to a non-uniform relationship between distance in the space and perceived similarity among the colors. The various versions of the color solid are examples of color spaces, each of which makes its particular departures from the ideal because of the purposes for which it was constructed (see again Hardin 1993). In addition, there are variations among normal individuals in the relations of similarity and difference that they will perceive. At a sufficiently detailed level of description there may not be any two observers that share the same color space.
} 
encode how a light would look. What is encoded is whether two lights will match-at least for the majority of us who approximate the "standard observer": the lights will match, or appear the same, just in case they have the same (or, more exactly, very close) tristimulus coordinates.

Consider a point $(\mathrm{X}, \mathrm{Y}, \mathrm{Z})$ in the tristimulus space, and another point that lies $n$ times further out on the same ray from the origin, $(n \mathrm{X}, n \mathrm{Y}, n \mathrm{Z})$. The corresponding second light needs primaries in the same ratio for a match, but $n$ more of each. Bearing in mind the three dimensions of color appearance (hue, saturation, and lightness), one might expect that the second light would appear brighter (lighter) than the first, with the same hue and saturation. This is indeed the case, to a close approximation. Hence, if the tristimulus space is reduced by one dimension by mapping each ray to a single point, we obtain a two dimensional space in which stimuli with different locations will appear to differ in hue and/or saturation. With a particular choice of axes, this space is displayed on the CIE chromaticity diagram, which is often annotated with the approximate color appearance of the stimuli, as in figure 1. 


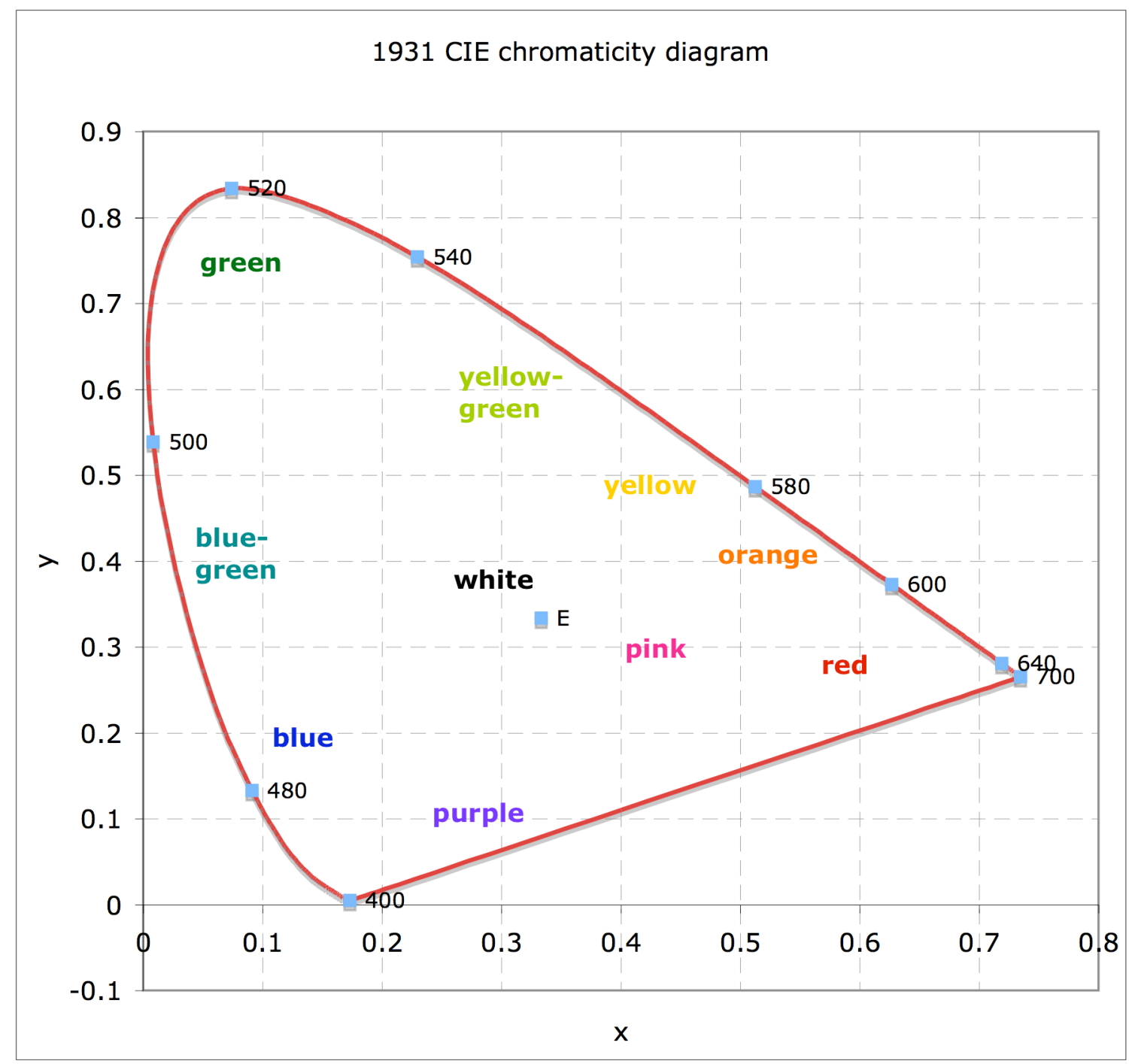

figure 1: 1931 CIE chromaticity diagram

The chromaticity coordinates $(\mathrm{x}, \mathrm{y})$ are derived from the tristimulus coordinates $(\mathrm{X}, \mathrm{Y}, \mathrm{Z})$ as follows: $\mathrm{x}=\mathrm{X} /(\mathrm{X}+\mathrm{Y}+\mathrm{Z}), \mathrm{y}=\mathrm{Y} / \mathrm{X}+\mathrm{Y}+\mathrm{Z} ;(\mathrm{x}, \mathrm{y})$ specifies the chromaticity of the corresponding light. The spectral (single-wavelength) lights are arranged around the horseshoe-shaped line, from spectral red on the bottom right (starting at 700nm, the approximate longwavelength end of the visible spectrum), green on the top, and violet on the bottom left (ending at $400 \mathrm{~nm}$, the short wavelength end). White is roughly in the middle: the chromaticity coordinates of the "equal energy white" light (marked 'E') are $(1 / 3,1 / 3) .{ }^{13}$ The lights become progressively less saturated as they approach white, as

\footnotetext{
${ }^{13}$ An equal energy light has a flat spectral power distribution.
} 
illustrated by the location of pink; the spectral lights are therefore maximally saturated. (In addition to the compression due to ignoring brightness, metamerism ensures that there is a many-one relation between stimuli and chromaticity.) The chromaticity diagram has the nice property that the chromaticity of any mixture of two lights lies on the line connecting the chromaticities of the two lights. Since any light is a mixture of spectral lights, this means that all stimuli lie in the region spanned by the horseshoe and a line (the "purple line") connecting its two endpoints. The fact that many chromaticity coordinates have no corresponding physical stimulus is due to the use of "imaginary" primaries. Bearing in mind the dangers of labeling the chromaticity diagram with color names, it is helpful to think of the "imaginary colors" outside the spectrum locus and purple line as more saturated instances of the hues that are found within them.

\subsection{Confusion lines}

As we mentioned at the beginning, there are two forms of red-green dichromacy. These are protanopia and deuteranopia: protanopes lack the L-photopigment, while deuteranopes lack the M-photopigment. (Tritanopes, the third kind of dichromat, lack the S-photopigment.) Consider a protanope. As one might expect, 700nm light at the far (red) end of the spectrum stimulates the L-cones and negligibly stimulates the M- or S-cones; $700 \mathrm{~nm}$ light is (near-enough) the L-cone primary (or fundamental). Suppose we take a spectral light (say, one of 520nm) and mix it with 700nm light. The protanope will not be able to distinguish the second light from the first (provided the second contains the same intensity of $520 \mathrm{~nm}$ light as the first), because the $700 \mathrm{~nm}$ light will not affect the M- and S-cones, and the protanope has no L-photopigment. So, given the way mixtures are represented on the chromaticity diagram, a line drawn from $700 \mathrm{~nm}$ to $520 \mathrm{~nm}$ specifies the chromaticities of stimuli that a normal observer can distinguish, but will match for a protanope - one of the protanope's confusion lines. Repeating this procedure for other spectral lights results in an array of confusion lines all converging on $700 \mathrm{~nm}$, the copunctal (or confusion) point, as illustrated in figure 2. 


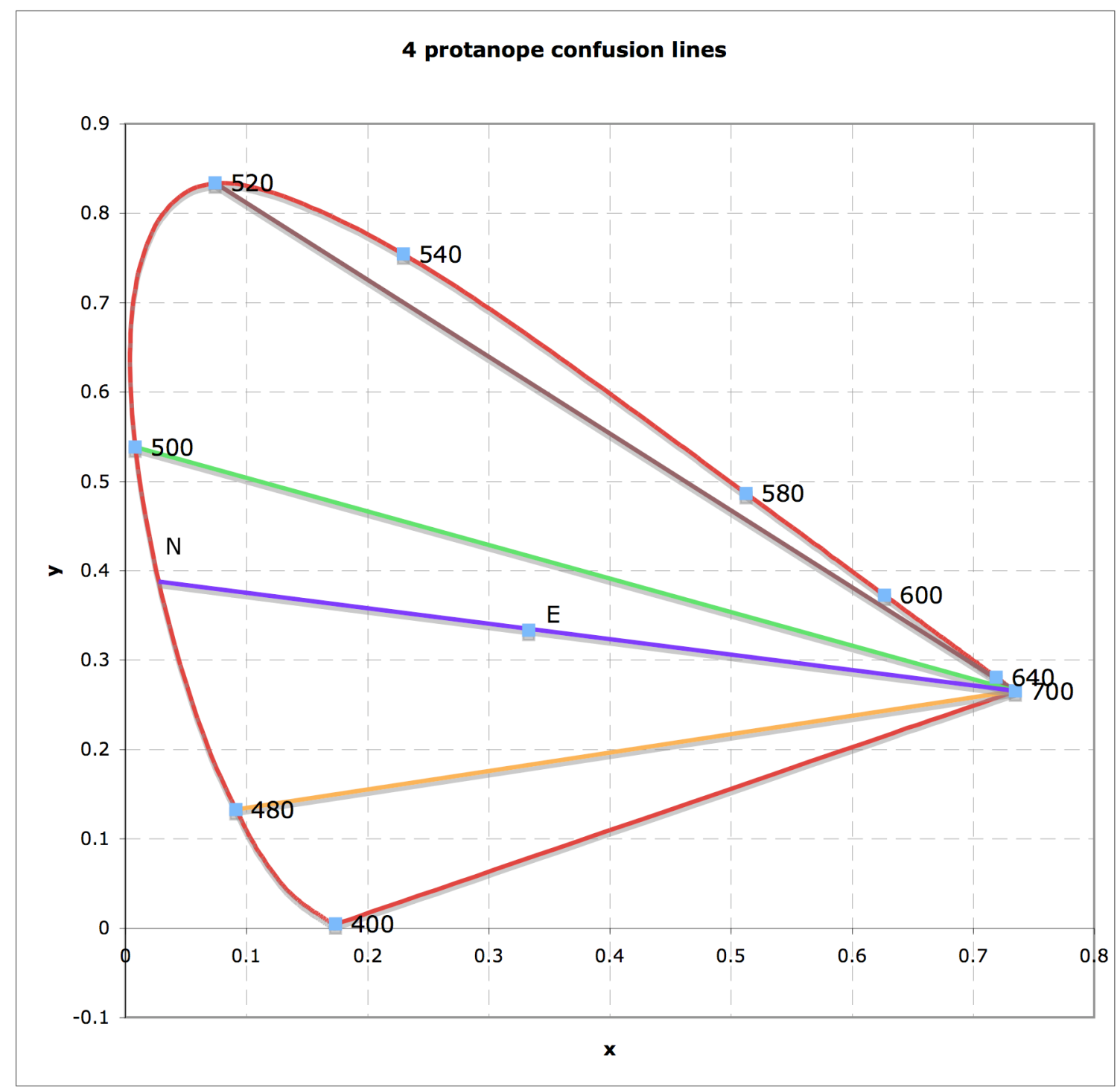

figure 2: 4 protanope confusion lines

One of the four confusion lines shown is of particular interest. It passes through the white point $\mathrm{E}$ and ends in the vicinity of $495 \mathrm{~nm}$, marked ' $\mathrm{N}$ ' on the diagram. Therefore a protanope will not be able to distinguish this region of the spectrum from a neutral white stimulus - $495 \mathrm{~nm}$ (or thereabouts) is the protanope's neutral point.

If two stimuli lie on the same confusion line, they will match (equating for brightness). The converse is also true. Suppose that two lights $l_{1}$ and $l_{2}$ lie on different confusion lines: $1_{1}$ from $700 \mathrm{~nm}$ to $\lambda_{1}$, and $l_{2}$ from $700 \mathrm{~nm}$ to $\lambda_{2}$. Then the first light has the same chromaticity as a mixture of light of wavelength $700 \mathrm{~nm}$ and $\lambda_{1}$, and the other as a mixture of $700 \mathrm{~nm}$ and $\lambda_{2}$. Now $\lambda_{1}$ and $\lambda_{2}$ will affect the M- and S-cones differently, 
otherwise they would lie on the same confusion line; adding an amount of 700nm light will make no difference, since that will not affect either the M- or S-cones. So the protanope will be able to distinguish $l_{1}$ and $l_{2}$. Hence, two stimuli lie on the same confusion line iff they match.

Similarly, deuteranopes and tritanopes will have their own distinctive confusion lines and neutral points. Since light of $400 \mathrm{~nm}$ stimulates the S-cones but not the M- or Lcones, the copunctal point for a tritanope will be (near-enough) at 400nm. However, because there is no light that just stimulates the M- cones the copunctal point for a deuteranope lies outside the region of real colors, at about $(.9,0)$ : the M-cone primary is, like the CIE primaries, “imaginary”. A deuteranope's neutral point is a little greener than a protanope's, at about $500 \mathrm{~nm}$.

The theoretical basis for the discrimination data just presented is entirely at the receptor level, with the following very simple assumption connecting receptor activity and discrimination. In the sort of matching experiments described two stimuli are discriminable just in case they have the same effects on the receptors. (For simplicity, we are ignoring the phenomenon of "just-noticeable differences".) No assumptions were made about the way color information is processed in the brain; in fact, even the dimensions of color appearance were ignored. Admittedly, the CIE chromaticity diagram has some labeled color regions to aid understanding, and it is intended to differentiate between stimuli with a different hue and/or saturation, but none of this information is necessary to predict matches.

Clearly, then, discrimination data cannot predict how things look to a dichromat. For all the discrimination data say, a green 510nm light looks to a dichromat exactly as an orange $620 \mathrm{~nm}$ light looks to a normal trichromat, or looks grey, or even looks to have a hue that normals never see. To make progress, different kinds of data are needed.

\subsection{Similarity}

Perceptual tasks involving arranging stimuli by similarity can help, but only up to a point. The Farnsworth-Munsell 15-D color blindness test consists of 15 differently colored caps of equal lightness and saturation, plus one reference cap. If asked to "arrange the caps in order according to color", starting with the reference cap, a red-green dichromat will choose a sequence that interleaves some red and green caps, and which approximates 
their order along the yellow-blue dimension (Jameson and Hurvich 1978: fig. 2). Shepard and Cooper (1992) asked subjects to arrange cards displaying pairs of colors in order of the similarity between the pairs. Multidimensional scaling produced the familiar color circle for normal subjects and (approximately) a line for dichromats. ${ }^{14}$ These sorts of result suggest that the dichromat's color space has two opposing hues, and that if these hues are familiar ones, they are yellow and blue. But that does not decide between the Reduction and Alien Views.

\subsection{Color language}

One obvious way of getting information about perceived hue is simply to ask the colorblind how things look. If, as the Reduction View has it, satsumas look yellow to deuteranopes, not orange, won't they admit this when questioned? Perhaps surprisingly, the matter is not this simple.

The color-blind, like the blind and those with other sensory deficits, learn native languages in their entirety, not some subset with the terms corresponding to their deficit subtracted. In the case of color blindness, where many individuals with the disorder are unaware of their condition, not only are a full set of color terms learned but they are applied to objects on the basis of how those objects look. That is, color terms like 'red' and 'blue' function for the color-blind much as they do for those with normal trichromatic vision. It isn't true, as Hacker claims, that the red-green color-blind "cannot use ['red' and 'green'] correctly in the way that we do, and will characteristically eschew their use" (1987: 152). Of course, the color-blind will sometimes mislabel the colors of things, but they will call tomatoes 'red' and grass 'green'. And neither do their everyday mistakes with color terms expose them as especially noteworthy linguistic deviants, contrary to Hacker's suggestion: the normally sighted also misapply terms for shades, especially relatively unusual ones like 'teal' and 'puce'. 15

We mentioned Dalton in $\S 1$; his description of his experience with English color language is instructive:

\footnotetext{
${ }^{14}$ The subjects were not (exclusively) dichromats, but had either a "strong deutan" or "strong protan" deficiency. That is, the subjects were either deuteranopes, protanopes, or had extreme forms of deuteranomaly or protanomaly (the two varieties of anomalous trichomacy). See note 2 above.

15 To say nothing of the notorious 'unique green' (Hardin 1993: 79-80).
} 
In the course of my application to the sciences, that of optics necessarily claimed attention; and I became pretty well acquainted with the theory of light and colours before I was apprized of any peculiarity in my vision. I had not, however, attended much to the practical discrimination of colours, owing, in some degree, to what I conceived to be a perplexity in their nomenclature... With respect to colours that were white, yellow, or green, I readily assented to the appropriate term. Blue, purple, pink, and crimson appeared rather less distinguishable; being according to my idea, all referable to blue. I have often seriously asked a person whether a flower was blue or pink, but was generally considered to be in jest. Notwithstanding this, I was never convinced of a peculiarity in my vision, till I accidentally observed the colour of the flower of the Geranium Zonale by candlelight, in the autumn of 1792. The flower was pink, but it appeared to me almost an exact sky-blue by day; in candle-light, however, it was astonishingly changed, not having then any blue in it, but being what I called red, a colour which forms a striking contrast to blue. (Dalton 1977: 520)

Notice that Dalton refers to a broad range of colors and that evidently his application of color terms to ordinary objects was not so eccentric as to convince him of the "pecularity" in his vision. Even his expertise in "the theory of light and colours" was not enough, with the discovery of his color blindness happening by chance.

Still, the color-blind face difficulties in using color terms, as Dalton recounts. As noted in the previous section, the perceived similarities among colored objects differ markedly between dichromats and trichromats (see again figure 2 in $\S 2.2$ ). Consequently the perceptible difference between, for example, objects correctly labeled 'cobalt' and those correctly labeled 'violet', is not at all obvious to dichromats. As Dalton saw it, there were just too many words marking overly subtle distinctions in certain regions of color space. However, despite his "perplexity" about nomenclature, Dalton appears to have used color language with tolerable accuracy.

Dalton's linguistic behavior in the greenhouse and potting shed suggests, if anything, that his color vision was near-enough normal. In fact, more careful investigation of his linguistic behaviour would probably have reinforced this incorrect conclusion. Jameson and Hurvich (1978) asked dichromatic subjects to name the 
Farnsworth-Munsell caps. The chosen names were quite similar to those of normal subjects. One deuteranope, in particular, behaved exactly like someone with normal color vision. Bonnardel (2006) required subjects to name 140 colored chips, presented individually against a grey background in random order using eight basic color terms. The agreement of the two deuteranopic subjects with a typical normal classification was $66 \%$ and $72 \%$, respectively.

Further, dichromats associate the correct similarity relations with color terms. In addition to the perceptual similarity task involving pairs of colors (see the previous section), Shepard and Cooper (1992) also elicited judgments of similarity using just pairs of color names. They found a circular similarity space that strongly resembled the similarity space of normal subjects.

So if dichromats can tell us how things look to them, the circumstances must be carefully chosen. In particular, the subjects must be able to set aside years of trying, and largely succeeding, to speak with the trichromatic majority. Consider the hue circle; in particular, the hue circle devised by the nineteenth century French chemist Michel Chevreul, divided into 72 sectors of equal angle: clockwise from top, green-olive-yelloworange-red-purple-violet-blue-turquoise, and back to green. ${ }^{16}$ Suppose we showed Chevreul's circle to a red-green dichromat who was aware of his deficit and explained to him the question of this paper. How would he describe the circle's colors?

William Pole, a professor of civil engineering at University College London, tried this experiment on himself, shortly after Chevreul had published his "Cercle Chromatique":

Now if I follow the Chevreul circle, starting from red [at the bottom], and going round, in the direction of a watch-hand, towards blue, in every division which I pass, the sensation of yellow becomes fainter and fainter...until very soon the yellow disappears altogether, and nothing but a dark grey or perfectly colourless hue remains...the blue I see perfectly, but the various tints of violet are to me only a darkened blue... at about the second or third division beyond "bleu vert," the blue has entirely disappeared, and nothing is left but a neutral grey. Beyond this

\footnotetext{
${ }^{16}$ A nice illustration of Chevreul's circle is at http://webexhibits.org/colorart/simultaneous.html
} 
the illumination begins to increase again, and at the same time a sensation of yellow begins to enter; the light and the colour both gradually heightening as I advance, until at the division "jaune" the darkening influence has entirely disappeared, and the full normal yellow hue is obtained. (Pole 1859: 329-8)

The hue circle, as Pole reports it, consists of two opposing chromatically colored sectors, blue and yellow, joined by two small achromatic regions centered around red and green. Other red-green dichromats have also succeeded in convincing themselves that they see things as either yellow, blue, or achromatic, just as the Reduction View predicts.

There are two problems, however. First, dichromats are not in agreement, and there are only a handful of published cases like Pole's. ${ }^{17}$ Second, and more importantly, even if we accept that Pole only sees two hues, we have not yet seen any compelling reason to think that these are yellow and blue. Granted, Pole sees lemons and satsumas as having the same hue $\mathrm{C}$, but why think that is yellow? After all, satsumas aren't yellow. Pole calls $\mathrm{C}$ 'yellow' but - assuming that lemons and bananas, but not satsumas, are the best exemplars of C-what else is he expected to call it? (Cf. Judd 1948: 248.)

\subsection{Opponent process theory}

One argument that Pole was right, albeit for uncompelling reasons, is based on the widely accepted opponent process theory of color vision. (See, e.g., Hardin 1993: 26-58, Kaiser and Boynton 1996: ch. 7.) According to it, color information is processed in three independent channels: red-green, yellow-blue, and white-black. The channels are

\footnotetext{
${ }^{17}$ Including (approximately) Dalton: "My yellow comprehends the red, orange, yellow and green of others; and my blue and purple coincide with theirs" (quoted in Sharpe et al. 1999: 29). On the other hand, according to Kaiser and Boynton, "Few dichromats can be convinced that their color vision accords with the theoretical description [the Standard Reduction View] just given" (1996: 453).

We asked a colleague who is a red-green dichromat (or severe anomalous trichomat) to describe a reproduction of Chevreul's circle. He replied: “All of the colours are out of my 'comfort zone'-I feel like I'm guessing all the way round. Noon: reddish [in fact this segment is green]. Shading off to green (??) at 2. Very unsure about this. Shading off to something darker at 4, but I can't tell if it's the same colour or not. Getting reddish around 5. 6 red, and I'm more confident about this than my previous guesses. Blue starts getting mixed in around 7:30. 9-10 definitely has blue in it, but it's not pure blue. Probably one of those 'purple/mauve' colours that I'm lousy at. 11 starts getting reddish again."
} 
antagonistic in the following sense: the output of the red-green channel, for example, is either biased towards red, or biased towards green, or at the balance point that is neither biased towards red or green. ${ }^{18}$ The output of the red-green channel depends on the difference of the output of the L- and M-cones (which we can label 'L' and ' $M$ '). Then (ignoring units, scaling, and other complications), if $\mathrm{L}-\mathrm{M}>0$ then the red-green channel is biased towards red, if $\mathrm{L}-\mathrm{M}<0$ it is biased towards green, and if $\mathrm{L}=\mathrm{M}$ then it is at the balance point. Similarly for the yellow-blue channel, which takes inputs from all three cone types: if $(\mathrm{L}+\mathrm{M})-\mathrm{S}>0$ it is biased toward yellow, if $(\mathrm{L}+\mathrm{M})-\mathrm{S}<0$ it is biased toward blue, and if $(\mathrm{L}+\mathrm{M})-\mathrm{S}=0$ the yellow-blue channel is at the balance point. The $\mathrm{S}$-cones make no contribution to the white-black channel, which becomes more biased towards white as $\mathrm{L}+\mathrm{M}$ increases. (All this is at best considerably oversimplified, but it will do for our purposes.)

Because deuteranopes and protanopes have, respectively, no M- and L-cones, one would expect them either to have non-functioning red-green channels, or else to lack them altogether. (This will be discussed further in $\$ 5.4$ below.) Similarly, the yellow-blue channel should be either inoperative or absent in tritanopes.

However, plausibly a deuteranope or protanope will have functioning yellow-blue and black-white channels. Hence opponent process theory leads naturally, if not inevitably, to a vindication of Pole and the Standard Reduction View: the colored world of deuteranopes and protanopes is much like ours, but with red and green missing. Things look blue, yellow, white, black, and grey, but nothing looks red, purple, green, or turquoise. (See, e.g., Hurvich 1981: 242-3, Hardin 1993: 145, Kaiser and Boynton 1996: 145.)

\subsection{Unilateral and acquired dichromacy}

The most direct source of data on color appearance for dichromats would be the testimony of a normal trichromat who became a dichromat for a day. This would require importing the experiences of a dichromat into the sensorium of a trichromat, which might

\footnotetext{
${ }^{18}$ One might reasonably ask what 'biased towards red' (e.g.) is supposed to mean; this is taken up in $\S 5.1$ below.
} 
sound medically impossible, if not conceptually confused. However, there are two actual conditions that resemble this procedure.

First, there are rare individuals who have (relatively) normal color vision in one eye and who exhibit one of the three types of congenital dichromacy in the other. These individuals would appear to be able to make the required direct comparison. They see the usual range of colors with their normal eye, and so they are able to compare this range with the colors they see with their dichromatic eye.

The results of this research are suggestive, although not conclusive. Two basic techniques account for most of the data. Unilateral dichromats can be asked to describe stimuli presented to the dichromatic eye or they can be asked to match stimuli between the two eyes. For unilateral protanopes and deuteranopes, the evidence is generally in agreement with the Standard Reduction View. They describe stimuli presented to the dichromatic eye as yellowish and bluish and the only stimuli that match across the two eyes are those that are unique yellow and unique blue as seen with the normal eye. (See Judd 1948, Sloan and Wollach 1948, Jackson 1982, Ruddock 1991 but compare MacLeod and Lennie 1976.) There are some complications here, sometimes with the data, but also with the exact nature of the subjects' color vision. In a significant fraction of the small number of subjects studied the "normal" eye itself is anomalous to varying degrees. In addition, there are cortical interactions between the two eyes relevant to perceived color and consequently the central processing of color signals from the normal eye may reflect the influence of a history of stimulation by the abnormal eye as well. ${ }^{19}$

Second, there are trichomatic individuals who become dichromats as the result of injury or disease. Acquired dichromacy, as opposed to some more complicated disturbance of color vision, is quite rare and identified cases tend to involve loss of Scone function, rather than M- or L-cone function (Sperling 1991). It is quite common in acquired color vision defects for both red-green and yellow-blue systems to be affected to varying degrees and they are usually associated with other disorders of vision. Acquired defects are typically unstable and often spatially varied with one eye more affected than

\footnotetext{
${ }^{19}$ For useful discussions of differences in the processing of signals from the two eyes of unilateral dichromats see MacLeod and Lennie 1976 and Alpern et al. 1983.
} 
the other or regions within the eye varying in the degree and nature of the impairment. The endpoint is often complete blindness rather than color blindness. The impairments also need not be the straightforward loss of color discrimination seen in the inherited dichromacies. For example, some acquired color vision defects take the form of chromatopsia, in which an endogenous color is added to the perceived object color (Krastel and Moreland 1991). Although the development of impairment is often rapid enough to be noticeable to subjects there is no useful published data on color change deriving from acquired dichromacy. This is presumably due to the rarity of the condition and the difficulty of making color comparisons over time periods of weeks to months.

Acquired dichromacy is of little help, then. However, the evidence from unilateral protanopia and deuteranopia supports the Standard Reduction View. ${ }^{20}$

\section{The Standard Reduction View}

So far, we have seen that the Standard Reduction View has a lot to be said for it (we will now drop 'Standard' when the context makes it clear). This section elaborates the Reduction View further, ending with a discussion of three problems. The first two are only apparent; the third is more serious. ${ }^{21}$

\footnotetext{
${ }^{20}$ Unilateral tritanopia is a different story. There are no well-characterized cases of congenital unilateral tritanopia and the cases of acquired unilateral tritanopia that have been reported do not fit any simple version of the Reduction View (Graham et al. 1967, Alpern et al. 1983). In light of the very small number of cases it would be a mistake to place any great weight on this difficulty.Taken at face value, the reported cases seem to conflict with the predictions of the Standard Reduction View. On the other hand, unilateral tritanopes are willing to use standard color terms to characterize the appearance of stimuli presented to their tritanopic eye and they are willing to accept matches between stimuli presented to the dichromatic eye and the normal eye. These last two points provide support for the truth of some form of the Reduction View although not for the Standard version in particular.

${ }^{21}$ A fourth problem for the Reduction View is posed by a cluster of empirical results. In color naming experiments putative dichromats use red and green (or all eleven basic color terms) in systematic and repeatable ways (Scheibner and Boynton 1968, Wachtler et al. 2004). It is not entirely clear how much of the color naming performance can be explained on the basis of color naming strategies adopted by dichromats living in a trichromatic culture. In addition some putative dichromats are trichromatic for larger stimuli (Smith and Pokorny 1977). Although the interpretation of the results of these and similar
} 


\subsection{The Reduction View elaborated}

Let us stick to protanopes for ease of illustration. The Reduction View tells us what the range of perceivable colors is for a protanope-the protanope's gamut. If we take a familiar three-dimensional color space, with the colors arranged along two-dimensions of hue (red-green and yellow-blue), and one achromatic dimension (black-white), then the protanope's color space is just a two-dimensional plane spanned by the yellow-blue and white-black axes. However, what this doesn't tell us is how particular stimuli look to a protanope. For all that's been said, a protanope might see a banana as blue.

However, once the Reduction View is granted, this further issue is reasonably tractable. Certain stimuli in a normal will keep the red-green channel in balance; plotted on a chromaticity diagram these stimuli will be all and only those that are mixtures of spectral unique blue (approximately 475nm) with white, and spectral unique yellow (approximately 580nm) with white - the gamut of the protanope, consisting of the variously saturated shades of unique blue and unique yellow (ignoring lightness). Since mixtures lie along straight lines, the stimuli that keep the red-green channel in balance will lie on the curve consisting of the line connecting $475 \mathrm{~nm}$ with the white point $\mathrm{E}$ (or thereabouts), and the line connecting E with 580nm. As far as the appearance of these stimuli go, the normal trichromat's red-green system seems to be irrelevant. Hence these stimuli, as displayed in figure 3 below, should (at least approximately) appear the same to a protanope (and, by the same token, to a deuteranope) as they do to a normal.

experiments is not straightforward it may be the case that inputs from the rods are capable of driving an extra color channel (Buck et al. 2006). For reasons of space we will set these complications aside. 


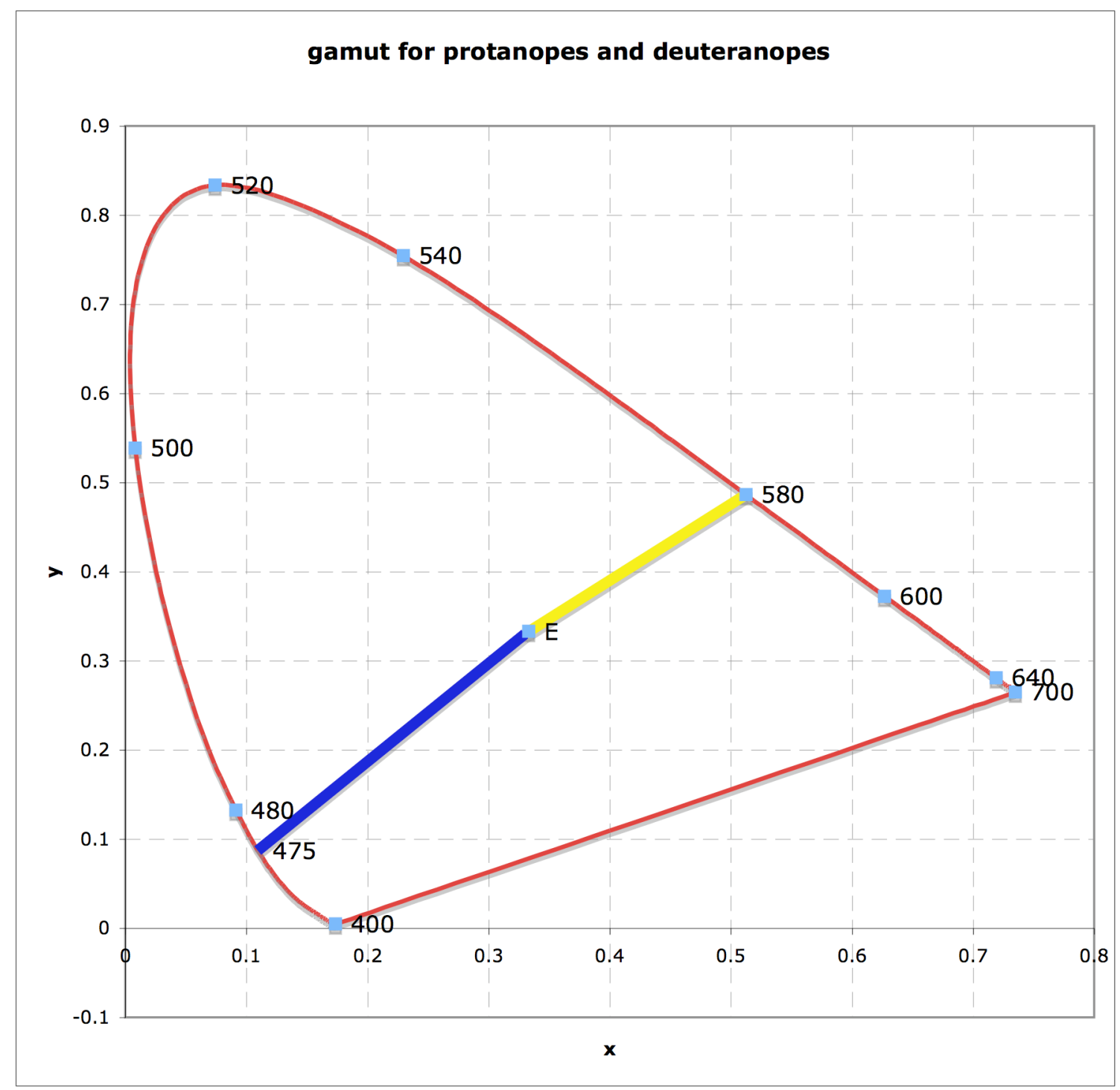

figure 3: gamut for protanopes and deuteranopes (on Standard Reduction View)

With the usual rule of thumb connecting color appearances (in the viewing conditions of the color matching experiment), figure 3 may also be taken approximately to represent how stimuli lying on the two lines meeting at $\mathrm{E}$ look to a protanope.

But that's not all the stimuli, of course - what about the rest, the vast majority? The facts about confusion lines mentioned in $\S 2.2$ provide the answer. Take some stimulus $\mathrm{T}$, say one in the purple region of the diagram. The protanope will not be able to distinguish between $\mathrm{T}$ and a stimulus $\mathrm{S}$ whose chromaticity coordinates are at the intersection of the confusion line passing through $\mathrm{T}$, and the curve in figure 3 , as illustrated in figure 4. 


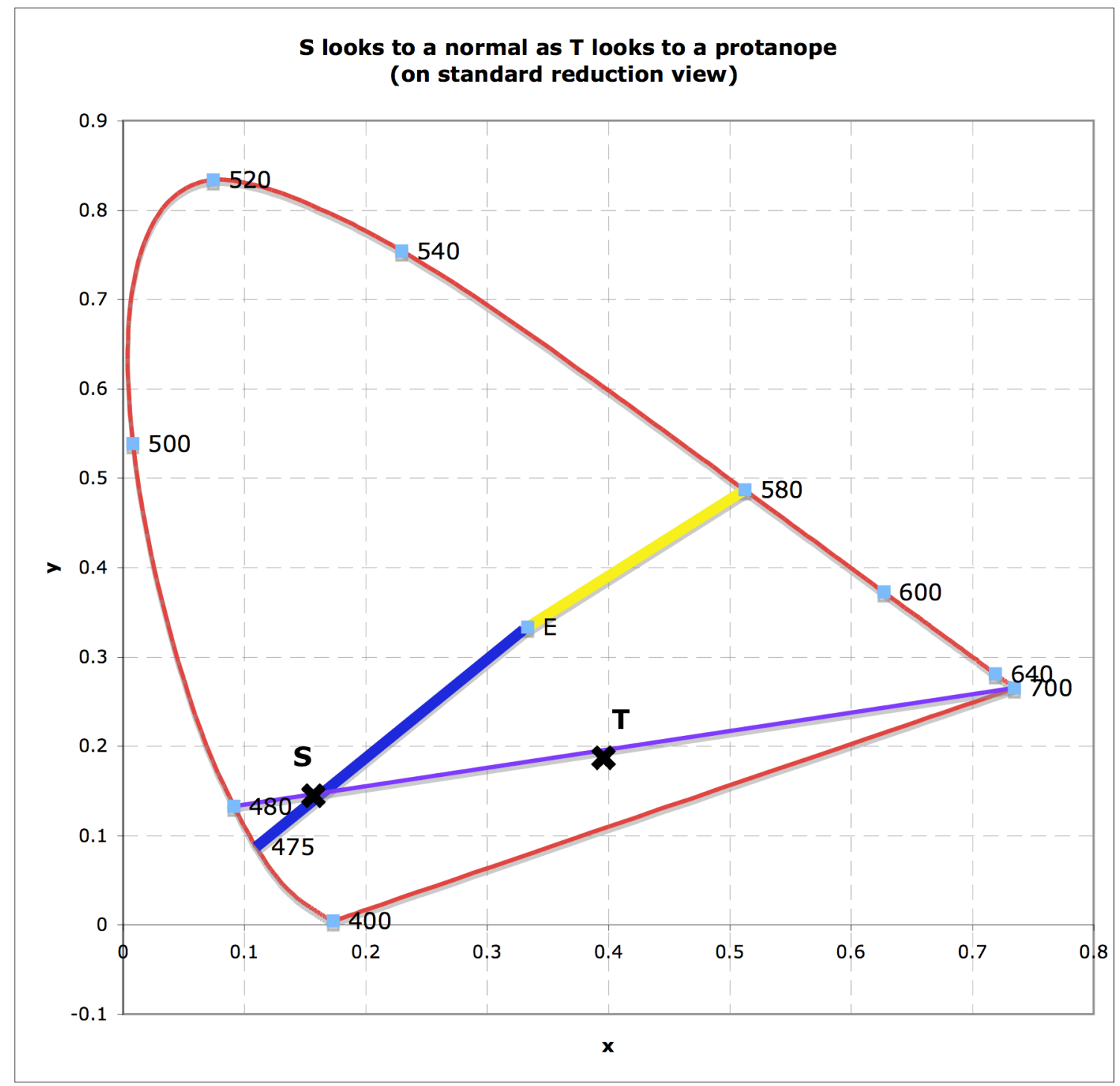

figure 4: S looks to a normal as T looks to a protanope

Since S looks the same to a normal as it does to the protanope, and since S looks to a normal to be a fairly saturated blue, that is how T will look to the protanope. Purple and turquoise stimuli will (tend to) look blue, and orange and olive stimuli will (tend to) look yellow.

Using these sorts of assumptions (with a number of sophisticated variations), a full-color image $\mathrm{I}_{\mathrm{T}}$ can be converted into a reduced color image $\mathrm{I}_{\mathrm{S}}$ that appears to a 
normal the way $\mathrm{I}_{\mathrm{T}}$ appears to a protanope; and similarly for the other two forms of dichromacy. $^{22}$

\subsection{Problems for the Reduction View}

However, the Reduction View is not entirely free from difficulty. This section discusses three problems. The first two are not at all serious; the third is more difficult.

\subsubsection{Problem 1: white, grey, and black}

According to the Reduction View, various chromatically colored stimuli will be perceived by a protanope as white — spectral light around the neutral point of $495 \mathrm{~nm}$, for instance (see figure 2 above). However, light of this wavelength is bluish-green (or so normal trichromats say), not white. Because they lack a long-wavelength receptor type, reds look dark to protanopes and are often mistaken for blacks: "On one occasion, a gentleman seeing a lady... in church wearing what seemed to him 'a black bonnet' asked her 'for whom she was in mourning, and surprised her greatly by the question, for her bonnet was of crimson velvet", ${ }^{23}$ A protanope will misperceive a variety of chromatically colored stimuli as white, grey, or black. Isn't it unacceptable to suppose that the protanope is in error?

No it isn't. Misperception itself is not a problem — normal trichromats will also sometimes misperceive chromatic stimuli as achromatic. And it is hardly surprising that dichromats will be more error-prone than trichromats: if one wants to detect whether stimuli are white, grey, or black, three receptor types are better than two (and, by the same token, four are better than three).

Further, two is good enough. Viewing natural scenes, a dichromat will not usually misperceive chromatic stimuli as achromatic.

\subsubsection{Problem 2: the missing shade of violet}

As can be seen from figure 4, stimuli that lie below a confusion line ending at $475 \mathrm{~nm}$ (which cluster at the violet end around 400nm) do not lie on a confusion line that

\footnotetext{
22 See, in addition to Brettel et al. 1997 and Viénot et al. 1995, Capilla et al. 2004.

${ }^{23}$ This is from George Wilson, Researches on Colour Blindness: with a supplement on the danger attending the present system of railway and marine coloured signals (1855), quoted by Hurvich (1981:
} 241). 
intersects the curve representing the protanope's gamut. A protanope will be able to see these stimuli, yet on the Reduction View, there is no way for them to appear! How can this be?

This problem can be solved by extending the protanope's gamut past the spectrum locus in the chromaticity diagram. These stimuli will have the same hue but will be more saturated than any color seen by someone with normal color vision. There is thus no corresponding color in the normal gamut and the procedure given above for finding corresponding colors will fail for some colors in the protanope's gamut. Another way to put the point is to observe that the spectrum locus for protanopes need not occupy the same position in the chromaticity diagram as it does for normal trichromats. And on the Reduction View it won't: reducing normal trichromatic vision to protanopic vision results in a shift in the appearance of the spectrum towards greater saturation.

\subsubsection{Problem 3: hue misperception}

According to the Reduction View, various purple and turquoise stimuli will be perceived by a protanope as blue (see figure 4 above). Similarly, various orange and olive stimuli will be perceived as yellow. Since purple and turquoise stimuli are not blue, and orange and olive stimuli are not yellow, protanopes will misperceive a variety of stimuli as blue or yellow. Again, isn't it unacceptable to suppose that the protanope is in error?

This is more of a puzzler. A protanope is supposed to have a functioning yellowblue channel, although he lacks one of the front-end transducers. Consider a satsuma, which (being orange) biases the yellow-blue channel in the yellow direction. A normal trichromat does not misperceive the satsuma as yellow. So, one might have thought, a protanope won't misperceive it as yellow either-he has a functioning yellow-blue channel that is in (appproximately) the same state as the trichromat's. Yet, according to the Reduction View, the satsuma looks yellow to a protanope.

Relatedly, the Reduction View does lead to widespread misperception of natural scenes, as can be confirmed by looking at various dichromatic simulations. And since a protanope only sees unique yellow or unique blue, the precise hue of practically every yellow and blue object will be misperceived. Naturally occurring blue and yellow objects are not usually unique yellow or blue (the clear daylight sky being a notable exception). Bananas, for instance, are greenish when unripe and a little reddish when ripe. Normal 
trichromats will disagree on whether an object is unique blue- Tye's "puzzle of true blue" (2006a); red-green dichromats pose the puzzle of true blue in spades! $!^{24}$

Further, the Reduction View does not confine widespread misperception to human dichromats. Most mammals are dichromats, and according to the standard account of the evolution of primate trichromacy, around thirty million years ago gene duplication transformed the single longer-wavelength photopigment of our dichromatic ancestors into two, our current L- and M- photopigments. (For reviews see Jacobs and Rowe 2004 and Surridge et al. 2003.) This added a new red-green opponent channel to the existing yellow-blue channel. On the Reduction View, human red-green dichromacy can accordingly be thought of as something of an atavistic glimpse of our distant evolutionary history. If misperception is widespread among human red-green dichromats, then presumably it also is among the many dichromatic mammals who share versions of the ancient yellow-blue system of color vision.

The threat of widespread error will of course not bother eliminativists like Hardin, who think that nothing is colored and therefore that error is ubiquitous. But one might have thought that the standard theory of color blindness, like other standard theories in visual science, would take no official position on these philosophical debates. ${ }^{25}$

\section{The Alien View}

The Reduction View, as we have seen, has much in its favor. But the problem of hue misperception provides some motivation for the rival Alien View, on which the dichromat's gamut is not a subset of the normal trichromat's - specifically, a protanope does not see unique yellow and unique blue, but some other hues entirely. The Alien View - if not in the version just mentioned — occasionally surfaces in the philosophical literature. Hacker, for instance, claims that red-green dichromats see "Rubies, emeralds,

\footnotetext{
${ }^{24}$ See also Cohen et al. 2006, Tye 2006b, Byrne and Hilbert 2007b, Tye 2007, and note 15 above.

${ }^{25}$ But what about scotopic vision, when the only input is from the rods? Don't cats (and everything else) look grey in the dark? And since most things aren't grey, isn't scotopic vision infected with massive error? No, it isn't: viewed scotopically, objects look light and dark, but not grey. Turning the lights down is not like changing a color image to a black-and-white one.
} 
and clouds [as] gred", where gredness is a color not seen by the rest of us (Hacker 1987: $152) .^{26}$

It would be hasty to embrace the Alien View simply because of the problem of hue misperception. Is there anything more to be placed on the pro side of the ledger? We shall consider two related arguments. The first argument attempts to derive the Alien View from three premises. The first two are particularly important: that the relations of similarity and difference between the hues are essential to them ("Essence", for short), and (something close to) the thesis Johnston has called "Revelation" (1992: 138). The second argument takes off from the failure of the first.

Let us begin by elaborating the first two premises of the first argument.

\subsection{Essence and Revelation}

Essence - the first premise - is, in one version or another, something of a consensus view among philosophers. David Armstrong, in a defense of a physicalist theory of color, claims that the resemblance relations among the hues are internal, and so hold in every possible world (1987: 44). Hardin, although entirely unsympathetic with Armstrong's physicalism, agrees that "the hues have certain characteristics necessarily" (1993: 66), and clearly thinks that examples include resemblance relations, for instance that "red [is] more like orange than like blue" (120). Other equally prominent examples are easy to find. $^{27}$

Turn now to the second premise, Revelation: as Johnston explains it, it is the thesis that " $[\mathrm{t}]$ he intrinsic nature of canary yellow is fully revealed by a standard visual experience as of a canary yellow thing" (1992: 138; see also Hilbert 1987: 37-8), and likewise for the other colors. Revelation, at least as officially stated-we will come back to this later-implies the slightly weaker thesis of Revelation ${ }^{(-)}$, that anyone who can see canary yellow (for example) is in a position to know the intrinsic nature of canary yellow. Revelation $^{(-)}$is the second premise. It is weaker than Revelation because it does not imply anything about the source of the knowledge of the nature of canary yellow; in particular,

\footnotetext{
${ }^{26}$ However, Hacker's version of the Alien View has nothing to be said for it. He has mistakenly taken the fact that dichromats confuse reds, greens and greys to indicate that dichromats see red, green and grey objects as having the same hue.

${ }^{27}$ See Johnston 1992, Clark 1993.
} 
it does not imply that the source is "a standard visual experience as of a canary yellow thing".

Revelation and Revelation $^{(-)}$are powerful solvents. Whatever "intrinsic nature" precisely comes to, if the colors are physical properties then this is paradigmatically part of their intrinsic nature. ${ }^{28}$ Since seeing canary yellow does not put one in a position to know that canary yellow is a physical property (such-and-such reflectance type, say), Revelation $^{(-)}$(and so Revelation) imply that color physicalism is false. Perhaps partly for this reason, Revelation and similar theses are, unlike Essence, quite controversial. ${ }^{29}$

\subsection{The first argument for the Alien View}

Essence unaided does not imply the Alien View. By Essence, it is in the nature of unique yellow that it is more similar to orange than to green; by itself this implies nothing about whether there could be someone who can see only unique yellow and unique blue. Even if we add in Revelation ${ }^{(-)}$, the desired conclusion that such a perceiver is impossible doesn't follow. By Revelation ${ }^{(-)}$, someone who can see unique yellow is in a position to know everything about its nature. Hence, someone who can see unique yellow is in a position to know that it is more similar to orange than to green. Fine, but why does such a person need to be able to see orange and green? Why can't he be a red-green dichromat as the Reduction View has it, and be able to see only unique yellow and unique blue?

However, it does seem plausible that someone who can only see unique yellow and unique blue (and, hence, not orange or green) is not thereby in a position to know that unique yellow is more similar to orange than to green. ${ }^{30}$ (Red-green dichromats might well know this, but not, presumably, simply by reflecting on their color experience.) So why not add this as a third premise? By Essence and Revelation ${ }^{(-)}$, someone who can see unique yellow is in a position to know everything about its nature. Hence, someone who can see unique yellow is in a position to know that it is more similar to orange than to green. And since, by the third premise, this is not possible if one

\footnotetext{
${ }^{28}$ And so (we assume) are the similarity relations between colors (Johnston 1992: 152).

${ }^{29}$ For more discussion of Revelation, restoring some omitted details, see Byrne and Hilbert 2007a.

${ }^{30} \mathrm{Cf}$. Boghossian and Velleman: "the experience of seeing something as red does not by itself reveal that the property now in view has a yellower neighbor (orange) and a bluer neighbor (violet)" (1991: 129).
} 
only sees unique yellow and unique blue, it is not possible to see only these hues. Redgreen dichromats must see other hues, so the Alien View is true.

There two problems with this argument. The first, and simplest, is that both Revelation and Revelation ${ }^{(-)}$are far too strong to be plausible. In fact, our formulation of Revelation, although it follows the letter of the quotation from Johnston above, does not accurately capture what he has in mind. Johnston does not mean that simply seeing canary yellow in isolation is enough to discern its nature. A diverse range of experiences is needed - which may well include seeing canary yellow things next to red things, other shades of yellow, and so on. This, more modest, version of Revelation does not imply Revelation $^{(-)}$, and so is of no help to the Alien View.

Discussion of the second problem can be postponed, because the second attempt to establish the Alien View runs into similar sand. ${ }^{31}$

\subsection{The second argument for the Alien View}

The basic idea behind the first argument was that if one sees unique yellow (say), one must have information about the other colors, information which one cannot have if one does not actually see those colors. In particular, if one sees unique yellow and unique blue one has information about orange and green, information which one can only possess if one actually sees orange and green (or, at least, other colors). The second argument for the Alien View tries out this basic idea in a different way.

We know that the colors exclude each other simply on the basis of visual experience: if something is yellow it is not blue or green; if something is canary yellow it is not sky blue; if something is sky blue it is not navy blue. More to the point, if something is unique yellow-yellow with no hint of red or green, then it is not red.

How is this knowledge to be explained? One obvious and attractive proposal is that there must be something about the way colors are visually encoded that allows us to

\footnotetext{
${ }^{31}$ There is also a third problem, which is that the argument is in danger of proving too much. Consider Johnston's version of Essence ("Unity"), which is not restricted to hue: "Thanks to its nature and the nature of the other determinate shades, canary yellow, like the other shades, has its own unique place in the network of similarity, difference, and exclusion relations exhibited by the whole family of shades" (1992:
} 138). Substituting Unity for Essence, the conclusion of the argument is that dichromats can't even see achromatic colors. 
infer that they exclude one another. Consider, as an analogy, the names 'Bill' and 'Ben', which refer to certain individuals who happen to be, respectively, the man who has (exactly) seven cats, and the man who has (exactly) six cats. Bill and Ben "exclude" each other: if the visitor at the door is Bill he isn't Ben. However, information about the visitor encoded using 'Bill' is not going to allow us to draw this conclusion: we might know that the visitor is Bill and yet still reasonably wonder whether the visitor is Ben. On the other hand, switching from names to descriptions makes a useful inference available: 'The visitor is not the man who has six cats' is a logical consequence of 'The visitor is the man who has seven cats'.

If one sees unique yellow and also sees orange, one is then in a position to know that if something is unique yellow it is not orange. How could these two colors be represented in a way that would permit this conclusion to be drawn? The way 'unique yellow' is defined gives a clue: as Hardin puts it, unique yellow is "a yellow that is neither reddish nor greenish" (1993: 39). Suppose that when one sees an object $x$ as unique yellow (that is, when one one sees unique yellow), $x$ is represented as being yellow but neither reddish nor greenish. And suppose that when one sees orange (that is, one sees an object $y$ as orange), $y$ is represented as, to use Hardin's phrase, "some degree reddish and also [as] some degree yellowish", with these two components of "chromatic strength" being roughly equal (39). Then this would explain how seeing these colors puts one in a position to know that they exclude each other: given this kind of chromatic perceptual coding plus a bit of logic, it follows that if something is unique yellow it is not orange.

Having independently motivated this claim about the way colors are represented, we can make a second attempt to reach the Alien View. If unique yellow is represented as a yellow that is neither reddish nor greenish, then seeing unique yellow by itself should put one in a position to know that it is not reddish, hence not reddish and yellowish in roughly equal proportion, hence not orange. But someone who only sees unique yellow (and unique blue) could not know solely on the basis of color experience that if something is unique yellow then it is not orange. So: someone who sees unique yellow and unique blue must also see other colors, and therefore the Alien View is true. 
The chief problem with this argument lies in the last step, which combines one premise with another that varies inversely in plausibility. Why do we think that seeing unique yellow and unique blue alone is insufficient to know that unique yellow excludes orange? Because that information is apparently not present in the experiences of seeing unique yellow and unique blue. Contrariwise, if we have convinced ourselves by some philosophical argument that seeing unique yellow supplies the information that it excludes orange, then we have no reason to maintain that someone who sees only unique yellow and unique blue is not thereby in a position to know that unique yellow excludes orange.

Basically the same problem afflicts the first argument for the Alien View. One of its two premises, Revelation ${ }^{(-)}$, was derived from Revelation (in the strong form given above), and has no apparent support without it. Suppose we have convinced ourselves of the truth of Revelation: the nature of unique yellow is completely exposed by an experience of seeing that color, and so seeing unique yellow is sufficient to know that it is more similar to orange than to green. The third premise of the argument was that someone who sees only unique yellow and unique blue is not in a position to know this fact about the essence of unique yellow. However, establishing Revelation, and so Revelation $^{(-)}$, removes any reason to believe the third premise.

\section{The Reduction View revisited and revised}

The only obstacle to the Reduction View is the problem of hue misperception. This section argues that it can be removed.

\subsection{Opponent processes and the Reduction View again}

Let us return to the argument in $\S 2.5$ that leads from the opponent process theory to the Reduction View, and make it more explicit.

1. A red-green dichromat's chromatic information (or misinformation) about a stimulus is supplied solely by his (essentially normal) yellow-blue channel, since he has no functioning red-green channel.

2. Either the dichromat's yellow-blue channel is biased towards yellow, or it is biased towards blue, or it is in balance. 
3. If a perceiver's yellow-blue channel is biased towards yellow, the channel is supplying the information (or misinformation) to the perceiver that the stimulus is yellow; similarly for the other two cases.

By (2), there are three cases. Consider the first: a dichromat's yellow-blue channel is biased towards yellow. By (3), the dichromat is receiving the information that the stimulus is yellow; by (1), the dichromat has no other chromatic information. So, the total information concerning the hue of the stimulus is that it is yellow (in fact, unique yellow). Assuming that this information is present in how the stimulus looks, the stimulus will look yellow. Similarly for other two cases. Hence:

4. To a red-green dichromat, things either look yellow, blue, or achromatic.

The problem with this argument is that premise (3) is false. Recall the satsuma of §3.2.3. When viewed by a normal trichromat, her red-green channel is biased towards red, and her yellow-blue channel is biased towards yellow. The information in these two chromatic channels is supposed to be combined at some stage in perceptual processing to produce the perception of orange. A protanope looking at the satsuma is just getting information from his yellow-blue channel, since his red-green channel—if indeed he has one-is inoperative. According to premise (3), the information supplied by his yellowblue channel is that the satsuma is yellow, and that's why it looks yellow to him. Similarly, if we consider a tritanope looking at the satsuma, the information supplied by his red-green channel is that the satsuma is red. Returning to the trichromat, her perceptual information about the hue of the satsuma is the combination of the information in both channels; that is, the information in the protanope's yellow-blue channel and the tritanope's red-green channel. Now, "combining" the information that $\mathrm{p}$ with the information that $\mathrm{q}$ is just to conjoin these two propositions. But then we get the result that the perception of orange is the perception of yellow\&red, which is wrong - an orange satsuma is neither yellow nor red.

It might be objected that our assumption that when the yellow-blue channel is biased towards yellow it supplies the information that the stimulus is yellow is oversimplified: we have ignored the fact that the yellow-blue channel supplies information about degrees of yellowness and blueness. (Something like this complication 
is required, because when a stimulus is seen as slightly reddish-yellow, say, the red-green channel is slightly biased towards red and the yellow-blue channel is more heavily biased towards yellow; cf. Hardin on " $x$ percent red and $y$ percent yellow" (1993: 120).) But adding this complication makes no difference. Suppose that having some "degree of yellowness" or having "non-zero percent yellow"-whatever these expressions mean, exactly_entails being yellow. Then the argument from the opponent process theory to the Reduction View is essentially unchanged, and so is our objection against premise (3). Suppose, on the other hand, that having some "degree of yellowness" or having "nonzero percent yellow" does not entail being yellow. Then premise (3) is false to begin with.

If yellow-blue channel is "biased towards yellow" it does not - contrary to what the terminology suggests - signal that the stimulus is yellow. What does it signal instead? In a normal trichromat the channel is positive just in case the stimulus looks to have a hue from that half of the hue circle that starts in the yellowish-reds next to unique red, and runs through orange, yellow, and yellow-green, stopping just short of unique green. In short: just in case the stimulus looks (even a tiny bit) yellowish. ${ }^{32}$ Hence, if the yellowblue channel is biased towards yellow it signals that the stimulus is yellowish, a superdeterminable of the determinable yellow. Similarly, if the channel is negative it signals that the stimulus is bluish. The yellow-blue channel is misnamed-it should really be called the yellowishness-bluishness channel.

\subsection{The Revised Reduction View}

If the flawed argument from the opponent process theory is repaired to accommodate the fact that the yellow-blue channel supplies information about yellowishness and bluishness, not yellowness and blueness, then it supports the Revised Reduction View. On the Standard Reduction View, a red-green dichromat sees objects as either unique yellow or unique blue. On the Revised Reduction View, a red-green dichromat sees objects as either yellowish or bluish.

\footnotetext{
${ }^{32}$ Cf. Bradley and Tye 2001: 472; in Byrne and Hilbert 1997a: 278-80, ‘yellowish' was defined less inclusively.
} 
As advertised at the beginning, the Revised Reduction View might as well be called the Revised Alien View. Yellowishness is not an entirely alien hue-something is yellowish iff it is either yellowish-red, or orange, or yellow, or greenish-yellow, or yellowish-green. But it is alienish: normal trichromats never see this hue without seeing more determinate hues like orange and yellow. On the Revised Reduction View, a redgreen dichromat sees yellowishness unaccompanied.

Switching to the Revised Reduction View removes the problem of hue misperception (§3.2.3). To red-green dichromats, satsumas look yellowish, not yellow; and since they are yellowish, they are not misperceived. The ancient "yellow-blue" system of color vision is not excessively error prone after all, since the hues it detects are the more inclusive yellowishness and bluishness, not the relatively exclusive yellowness and blueness.

\subsection{Hue magnitudes}

The Revised Reduction View can be further elaborated and explained with the aid of the hue magnitude account of the visual representation of colors in Byrne and Hilbert 2003. ${ }^{33}$ In the terminology of that paper, there are four hue magnitudes, $\mathbf{R}, \mathbf{Y}, \mathbf{B}$, and $\mathbf{G}$, which come in degrees like length and temperature. 'Yellowishness' was used earlier to stand the property of having some degree or other of the $\mathbf{Y}$ magnitude; since context will disambiguate, we can use 'yellowishness' also to stand for the $\mathbf{Y}$ magnitude, and similarly for the other hue-ish terms.

When one sees an object as unique yellow it is represented as having a degree of yellowishness that is $100 \%$ of its total hue, the sum of its degrees of all the hue magnitudes. When one sees an object as orange it is represented as reddish to a degree that is roughly $50 \%$ of its total hue, and yellowish to the remaining degree.

This explains, incidentally, our knowledge of color exclusion (compare the proposal discussed in $\S 4.3$ ): if something is $100 \%$ yellowish it can't be roughly $50 \%$ yellowish, and so isn't orange.

The hue magnitude account is independent of the opponent process theory, which is not an account of the content of visual experience, but the two make a nice fit. The

\footnotetext{
${ }^{33}$ See also Byrne 2003.
} 
yellow-blue channel provides information about degrees of yellowishness and bluishness, and the red-green channel provides information about degrees of reddishness and greenishess. Together, these two channels contribute, to the content of visual experience, the relative proportion of yellowishness (bluishness) and reddishness (greenishness).

Consider, again, a normal trichromat and a protanope looking at our satsuma. Suppose that the trichromat's experience represents the satuma as having reddishness that is $40 \%$ of its total hue (the sum of the four hue magnitudes), and yellowishness that is $60 \%$ of its total hue. The protanope has no functioning red-green channel, and so the only two magnitudes represented by his visual experience are yellowishness and bluishness. For him, the "total hue" of the satsuma is a quantity that is the sum of its degrees of yellowishness and bluishness: call that the satsuma's total reduced hue. Combining the hue magnitude account and the Revised Standard View, the protanope's visual experience represents, not that the satsuma has yellowishness that is $100 \%$ of its total ("unreduced") hue, but rather that it has yellowishness that is $100 \%$ of its total reduced hue (the sum of its yellowishness and bluishness). The satsuma, then, is not represented as unique yellow, but rather as having some degree or other of the yellowishness magnitude - that is, as yellowish. ${ }^{34}$

\subsection{But is the red-green channel either inoperative or absent?}

The above argument for the Revised Standard View made use of an assumption first introduced in $\S 2.5$, namely that in protanopes and deuteranopes either the red-green channel is present but makes no contribution to color perception, or else is absent. Is that assumption plausible?

Suppose, on the contrary, that a functioning red-green channel is present: it develops in every human being whether there are appropriate cone types to supply it or not, and its output contributes to color perception. One possibility is that the channel output is permanently biased - towards greenishness for protanopes and reddishness for deuteranopes. If so, then the Standard Reduction View is wrong: the two hues seen by

\footnotetext{
${ }^{34}$ Similar considerations show that the "black-white" or "achromatic" channel is misnamed: it should be called the "dark-light" channel. If it were contributing information about the degree of greyness of the stimulus, then (since every stimulus affects the achromatic channel) everything would look grey to some degree.
} 
protanopes are yellow-green and blue-green and the two deuteranopic hues are orange and purple. Another (arguably more likely) possibility is that dichromatic visual system adapts to the unvarying red-green signal by setting the red-green channel output permanently to neutral. This would vindicate the Standard Reduction View: when a protanope looks at a satsuma his experience represents that the satsuma has yellowishness that is $100 \%$ of its total hue; that is, that the satsuma is unique yellow.

If either of these possibilities obtain then dichromacy is a kind of pathology, not just a less discriminating form of color vision than the trichromatic condition. On the first possibility, for instance, a protanope's color vision system signals greenishness, no matter whether the seen object is greenish or not. This is not merely a matter of error, but also of complete insensitivity: veridical perception of greenishness is an accident, like a stopped clock that reads the correct time. And similarly on the second possibility: veridical perception of an object that is neither reddish nor greenish will be a fluke.

However, the available evidence supports the conclusion that congenital dichromats, at least, have no functioning red-green channel. First, a general rule of visual processing is that unchanging inputs are ignored. For example, if an image is stabilized on the retina it fades to grey (Martinez-Conde et al. 2004). This is why we don't perceive in ordinary circumstances the shadows cast on the retina by the veins in the eye. If dichromats have a red-green channel there is no reason to think its output would contribute to their color experience.

Second, congenital dichromats might well not possess a red-green channel at all. Research on non-human color vision indicates that the processing of chromatic information, in particular, is not set by a pre-existing wiring diagram, but instead is driven by the kind of stimuli available. In some South American monkeys, M- and Lcone pigments are coded by two alleles on the $\mathrm{X}$-chromosome. The males and homozygous females thus have only two cone pigments and are dichromatic; heterozygous females have three and are trichromatic (Jacobs et al. 1993). (That is, heterozygous females are both retinally and functionally trichromatic.) Mice are normally dichromatic, but if an allele for a third cone pigment is inserted on the X-chromosome the heterozygous females will be trichromatic (Jacobs et al. 2007). This suggests that 
opponent channels emerge partly in response to the cone inputs, as opposed to being created independently.

\subsection{Unilateral dichromacy again}

According to the Revised Reduction View, red-green dichromats see yellowishness and bluishness, and not trichromatic hues like unique yellow and unique blue. Nevertheless, as we have seen, unilateral dichromats will describe stimuli presented to their normal eye exclusively as yellow and blue, and will accept matches between stimuli presented separately to their normal and dichromatic eyes. Is this a problem for the Revised Reduction View?

Not really. First, the Revised Reduction View does not obviously apply to unilateral dichromats. Central color processing and representation in unilateral dichromats, as opposed to bilateral dichromats, has developed in response to a mixture of dichromatic and trichromatic inputs. Because of this fact, it is a plausible conjecture that color is always represented by unilateral dichromats using the two-dimensional hue code of normal trichromats. If so, then some stimuli presented to a unilateral dichromats dichromatic eye really do look unique yellow and unique blue. This would explain why they accept matches between the two eyes, and use 'yellow' and 'blue' to label stimuli presented to the dichromatic eye. That the central mechanisms of unilateral dichromats may differ from those of bilateral dichromats presents a real problem in interpreting the data from unilateral dichromats, and has been appealed to, for example, to explain why the known cases of unilateral tritanopia deviate from the predictions of the Standard Reduction View (Alpern et al. 1983).

Second, even if unilateral dichromats are (improbably) cyclopean bilateral dichromats, and so see the bilateral's colors with their dichromatic eye, the matching and description data are consistent with the Revised Reduction View. Unless very careful measures are taken to ensure that subjects only accept complete perceptual matches, the fact that a subject accepts a match between two stimuli does not establish that they are perceptually identical, only that they are similar in a salient respect (see, for example, Arend and Reeves 1986). If we suppose that yellowishness and unique yellow are saliently similar, then matching experiments pose no difficulty. And given that the 
unilateral dichromat just has normal color vocabulary to describe stimuli presented to his dichromatic eye, it is not surprising that 'yellow' and 'blue' are the words of choice.

\section{Summary conclusion}

This paper has argued for the Revised Reduction View: red-green dichromats see the world as having two superdeterminable hues, yellowishness and bluishness. More cautiously: if dichromatic vision is a reduction of normal trichromatic vision, then the Revised Reduction View is true.

The colors we normal trichromats see are either determinables like yellow, orange, and blue, or determinates like canary yellow, coral, and navy blue. Red-green dichromats do not see any of these colors. In that sense, the vulgar are vindicated: redgreen dichromats are not just merely color deficient—-they are color-blind. 


\section{References}

Alpern, M., K. Kitahara, and D. H. Krantz. 1983. Perception of colour in unilateral tritanopia. Journal of Physiology 335: 683-97.

Arend, L., and A. Reeves. 1986. Simultaneous color constancy. Journal of the Optical Society of America A. Optics and Image Science 3: 1743-51.

Armstrong, D. M. 1987. Smart and the Secondary Qualities. Metaphysics and Morality: Essays in Honour of J. J. C. Smart, ed. P. Pettit, R. Sylvan and J. Norman.

Boghossian, P., and J. D. Velleman. 1991. Physicalist theories of color. Philosophical Review 100: 67-106 (page reference to the reprint in Byrne and Hilbert 1997a).

Bonnardel, V. A. L. 2006. Color naming and categorization in inherited color vision deficiencies. Visual Neuroscience 23: 637-43.

Boynton, R. M. 1979. Human Color Vision. New York: Holt, Rinehart and Winston.

Bradley, P., and M. Tye. 2001. Of colors, kestrels, caterpillars, and leaves. Journal of Philosophy 98: 469-87.

Brettel, H., F. Vienot, and J. D. Mollon. 1997. Computerized simulation of color appearance for dichromats. Journal of the Optical Society of America A. Optics and Image Science 14: 2647-55.

Buck, S. L., L. P. Thomas, N. Hillyer, and E. M. Samuelson. 2006. Do rods influence the hue of foveal stimuli? Visual Neuroscience 23: 519-23.

Byrne, A. 2003. Color and similarity. Philosophy and Phenomenological Research 66: 641-65.

Byrne, A., and D. R. Hilbert. 1997a. Colors and reflectances. Readings on Color, Volume 1: The Philosophy of Color, ed. A. Byrne and D. R. Hilbert. MIT Press.

- 2003. Color realism and color science. Behavioral and Brain Sciences 26: 3-21.

—. 2007a. Color Primitivism. Erkenntnis 66: 73-105.

—. 2007b. Truest blue. Analysis 67: 87-92.

—. (eds.) 1997b. Readings on Color, Volume 1: The Philosophy of Color. Cambridge, MA: MIT Press. 
Capilla, P., M. A. Díez-Alenjo, M. J. Luque, and J. Malo. 2004. Corresponding-pair procedure: a new approach to simulation of dichromatic color perception. Journal of the Optical Society of America A. Optics and Image Science 21: 176-86.

Chalmers, D. J. 2002. Philosophy of Mind: Classical and Contemporary Readings. Oxford: Oxford University Press.

Chisholm, R. M. 1957. Perceiving: A Philosophical Study. Ithaca: Cornell University Press.

Clark, A. 1993. Sensory Qualities. Oxford: Oxford University Press.

Cohen, J., C. L. Hardin, and B. P. McLaughlin. 2006. True colours. Analysis 66: 335-40.

Dalton, J. 1977. John Dalton's discovery of his colour blindness. Applied Optics 16: 520.

Edridge-Green, F. W. 1911. The Hunterian Lectures on Colour-Vision and ColourBlindness. London: Kegan Paul, Trench, Trübner \& Co., Ltd.

Graham, C. H., Y. Hsia, and F. F. Stephan. 1967. Visual discriminations of a subject with acquired unilateral tritanopia. Vision Research 6: 469-79.

Hacker, P. M. S. 1987. Appearance and Reality. Oxford: Blackwell.

Hardin, C. L. 1993. Color for Philosophers: Unweaving the Rainbow (expanded edition). Indianapolis: Hackett.

Hilbert, D. R. 1987. Color and Color Perception: A Study in Anthropocentric Realism. Stanford: CSLI.

Hunt, D. M., K. S. Dulai, and J. K. Bowmaker. 1995. The chemistry of John Dalton's color blindness. Science 267: 984-8.

Hurvich, L. M. 1981. Color Vision. Sunderland, MA: Sinauer Associates Inc.

Jackson, F. 1977. Perception: A Representative Theory. Cambridge: Cambridge University Press.

—. 1982. Epiphenomenal qualia. Philosophical Quarterly 32: 127-36. Page reference to the reprint in Chalmers 2002.

Jacobs, G. H., J. Neitz, and M. Neitz. 1993. Genetic Basis of Polymorphism in the Color Vision of Platyrrhine Monkeys. Vision Research 33: 269-74.

Jacobs, G. H., and M. P. Rowe. 2004. Evolution of vertebrate colour vision. Clinical and Experimental Optometry 87: 206-16. 
Jacobs, G. H., G. A. Williams, H. Cahill, and J. Nathans. 2007. Emergence of novel color vision in mice engineered to express a human cone pigment. Science 315: 1723-5.

Jameson, D., and L. M. Hurvich. 1978. Dichromatic color language: "reds" and 'greens" don't look alike but their colors do. Sensory Processes 2: 146-55.

Johnston, M. 1992. How to speak of the colors. Philosophical Studies 68: 221-63 Page reference to the reprint in Byrne and Hilbert 1997a.

Judd, D. B. 1948. Color perceptions of deuteranopic and protanopic observers. Journal of Research of the National Bureau of Standards 41: 247-71.

Kaiser, P. K., and R. M. Boynton. 1996. Human Color Vision. 2nd ed. Washington, DC: Optical Society of America.

Krastel, H., and J. D. Moreland. 1991. Colour vision deficiencies in ophthalmic diseases. Inherited and Acquired Colour Vision Deficiencies: Fundamental Aspects and Clinical Studies, ed. D. H. Foster. Boston: CRC Press.

MacLeod, D. I. A. 1985. Receptoral constraints on color appearance. Central and Peripheral Mechanisms of Color Vision, ed. D. Ottoson and S. Zeki. London: Macmillan.

MacLeod, D. I. A., and P. Lennie. 1976. Red-green blindness confined to one eye. Vision Research 16: 691-702.

Martinez-Conde, S., S. L. Macknik, and D. H. Hubel. 2004. The role of fixational eye movements in visual perception. Nature Reviews Neuroscience 5: 229-39.

Pokorny, J., M. Lutze, D. Cao, and A. J. Zele. 2006. The color of night: surface color perception under dim illuminations. Visual Neuroscience 23: 525-30.

Pole, W. 1859. On colour-blindness. Philosophical Transactions of the Royal Society of London 149: 323-39.

Ruddock, K. H. 1991. Psychophysics of inherited colour vision deficiencies. Inherited and Acquired Colour Vision Deficiencies: Fundamental Aspects and Clinical Studies, ed. D. H. Foster. Boston: CRC Press.

Scheibner, H. M. O., and R. M. Boynton. 1968. Residual red-green discrimination in dichromats. Journal of the Optical Society of America 58: 1151-8. 
Sharpe, L. T., A. Stockman, and H. Jägle. 1999. Opsin genes, cone photopigments, color vision, and color blindness. Color Vision: From Genes to Perception, ed. K. R. Gegenfurtner and L. T. Sharpe. Cambridge: Cambridge University Press.

Shepard, R. N., and L. A. Cooper. 1992. Representation of colors in the blind, colorblind, and normally sighted. Psychological Science 3: 97-104.

Sloan, L. L., and L. Wollach. 1948. A case of unilateral deuteranopia. Journal of the Optical Society of America 38: 502-9.

Smith, V. C., and J. Pokorny. 1977. Large-field trichromacy in protanopes and deuteranopes. Journal of the Optical Society of America 67: 213-20.

Sperling, H. G. 1991. Vulnerability of the blue-sensitive mechanism. Inherited and Acquired Colour Vision Deficiencies: Fundamental Aspects and Clinical Studies, ed. D. H. Foster. Boston: CRC Press.

Stabell, B., and U. Stabell. 1998. Chromatic rod-cone interaction during dark adaptation. Journal of the Optical Society of America A. Optics and Image Science 15: 2809815.

Surridge, A. K., D. Osorio, and N. I. Mundy. 2003. Evolution and selection of trichromatic vision in primates. Trends in Ecology and Evolution 18: 198-205.

Thau, M. 2002. Consciousness and Cognition, Philosophy of mind series. New York: Oxford University Press.

Thomas, L. P., and S. L. Buck. 2006. Foveal and extra-foveal influences on rod hue biases. Visual Neuroscience 23: 539-42.

Tye, M. 2006a. The puzzle of true blue. Analysis 66: 173-8.

- 2006b. The truth about true blue. Analysis 66: 340-4.

- 2007. True blue redux. Analysis 67: 92-3.

Viénot, F., H. Brettel, L. Ott, A. B. M'Barek, and J. D. Mollon. 1995. What do colourblind people see? Nature 376: 127-8.

Wachtler, T., U. Dohrmann, and R. Hertel. 2004. Modeling color percepts of dichromats. Vision Research 44: 2843-55. 